\title{
ÉTICA DA CIÊNCIA: EDUCAÇÃO E DIFUSÃO SÃO IMPRESCINDÍVEIS
}

O desenvolvimento de pesquisa científica em nosso país envolvendo número significativo de pessoas é comparativamente recente, tanto que o próprio $\mathrm{CNPq}$ - Conselho Nacional de Desenvolvimento Científico e Tecnológico - tem pouco mais de 60 anos de existência, e o Ministério da Ciência, Tecnologia e Inovação só tem existência estável há cerca de 21 anos. Mas, foi a institucionalização das atividades de pós-graduação stricto sensu, há menos de 50 anos, ${ }^{1}$ e seu significativo crescimento nas últimas três décadas, que dotou o país de um sistema de formação pós-graduada e de pesquisa mais pujante. A partir de 2000, passou-se a titular anualmente mais de 5 mil doutores, já superando-se os 10 mil a partir de $2008 .{ }^{2}$ Assim, na última década, aos poucos começou a ser mais significativo o número de estagiários de pós-doutorado nos laboratórios de pesquisa, contribuindo para a consolidação do sistema.

Com esta significativa expansão do sistema de pesquisa e de formação de futuros pesquisadores, também passaram a ser mais frequentes as denúncias de casos de má conduta científica, resultando em anulações de títulos, demissões, retratações de artigos, reprovações de defesas, etc. Aumentou, assim, a preocupação com os aspectos éticos da atividade científica, tanto que, em maio de 2011, instada a manifestar-se sobre denúncia de fraude em publicações científicas envolvendo pesquisadores apoiados pelo CNPq, a sua Diretoria Executiva decidiu nomear uma comissão especial "com a missão de propor recomendações e diretrizes sobre o tema da Ética e Integridade na Prática Científica". ${ }^{3}$ No relatório desta comissão ${ }^{4}$ constam 21 diretrizes básicas para a integridade na atividade de pesquisa, porém bastante focadas na questão da publicação de resultados de pesquisa. A seguir, ainda em 2011, o Conselho Deliberativo do CNPq aprovou a instituição da Comissão de Integridade da Atividade Científica, ${ }^{5}$ com atribuições gerais e específicas voltadas à prevenção, educação e investigação da integridade da pesquisa realizada e/ou publicada por pesquisadores em atividade no Brasil. Já a CAPES - Coordenação de Aperfeiçoamento de Pessoal de Nível Superior, em janeiro de 2011, com base em orientações do Conselho Federal da Ordem dos Advogados do Brasil (OAB), divulgou às instituições de ensino públicas e privadas brasileiras recomendações de combate ao plágio. ${ }^{6}$ Por outro lado, a Coordenação da Área de Química da CAPES, responsável pelo acompanhamento e avaliação dos programas de pós-graduação da área, em seu Comunicado $n^{\circ} 003 / 2011$, oportunamente incentivou que todos os programas implementassem disciplinas, seminários, simpósios ou workshops para discutir aspectos relacionados à ética em pesquisa científica e em publicações. ${ }^{7}$

Também em 2011, a Fundação de Amparo à Pesquisa do Estado de São Paulo (FAPESP) divulgou seu Código de Boas Práticas, ${ }^{8}$ contendo diretrizes éticas para as atividades científicas (abarcando desde a concepção, proposição e realização da pesquisa, até a comunicação de seus resultados e autoria, o registro, conservação e acessibilidade de dados e informações, o conflito potencial de interesses, a avaliação pelos pares, e a tutoria) e discorrendo sobre as más condutas científicas, as responsabilidades das instituições de pesquisa, e sobre a alegação, a investigação e a declaração de más condutas científicas. Em seguida, a revista Pesquisa FAPESP, mensal, passou a ter a coluna "Boas Práticas", para

destacar casos internacionais relevantes de combate a fraudes científicas. Por uma rápida busca nos sítios de algumas outras importantes fundações estaduais de amparo à pesquisa do país, constatei que ainda não dão qualquer destaque à questão da integridade da atividade científica.

Considero, pelo acima exposto, que foram significativos os avanços ocorridos na formalização de aspectos da integridade da atividade de pesquisa, pelo CNPq, em nível nacional, e pela FAPESP, em nível estadual. Entretanto, entendo que muito mais precisa ser feito, pois só com educação e difusão contínuas minimizar-se-á a ocorrência de más condutas.

Cabe destacar que Química Nova já vem dando sua contribuição, sendo que desde 2006 a questão "ética e ciência" foi abordada nesta página editorial diversas vezes. ${ }^{10-14} \mathrm{Na}$ primeira delas, ${ }^{10} \mathrm{em}$ que foram tecidos comentários e reflexões sobre fraude do cientista sul-coreano Hwang Woo Suk relacionada à clonagem de embriões humanos, já foi enfatizada a importância da honestidade e retidão ética na atividade de pesquisa e na divulgação de seus resultados, bem como da transmissão desses valores aos alunos. Na segunda delas, os editores discorreram sobre aspectos éticos relacionados à publicação de artigos científicos, em especial as obrigações e cuidados éticos que os seus autores devem ter. ${ }^{11}$ No ano seguinte, a ocorrência de fraudes e plágios em artigos científicos foi abordada, no contexto de desvios éticos (fraudes) constatados em alguns currículos na Plataforma Lattes do CNPq. ${ }^{12}$ Mais recentemente,,$^{13}$ os editores discorreram especificamente sobre a questão do plágio, finalizando com a conclusão de que só educação e conscientização levarão a algum resultado. $\mathrm{Na}$ última vez, ${ }^{14}$ ao discorrer sobre o tema da então futura $35^{\text {a }}$ Reunião Anual da SBQ, "Responsabilidade, Ética e Progresso Social", os editores voltaram a mencionar desvios éticos em publicações científicas, chamando atenção ao Código de Boas Práticas da FAPESP, que acabara de ser lançado.

Como já mencionei, precisamos avançar ainda mais; para isto, é fundamental a contribuição de todas as instâncias envolvidas no processo de produção e divulgação de conhecimento. Assim, todas as agências de fomento, nacionais e estaduais, devem adotar e divulgar diretrizes claras e abrangentes sobre integridade da atividade científica. Além disso, sempre que possível e oportuno, devem promover e/ ou apoiar atividades educativas sobre este tema. Por outro lado, todas as instituições de ensino e pesquisa, locais onde 
a pesquisa efetivamente se materializa, também devem ter suas diretrizes, destacando-se neste caso os procedimentos de acolhimento e investigação de denúncias, bem como de adequada instrução e proteção de denunciantes (neste sentido, diversas sugestões podem ser encontradas em artigo de Gunsalus ${ }^{15}$ ). Ademais, todas as associações profissionais e mesmo estudantis também devem ter seus códigos de ética; neste sentido a própria Sociedade Brasileira de Química (SBQ) ainda necessita avançar, como já o fizeram há tempos congêneres como a American Chemical Society ${ }^{16}$ ou a Royal Society of Chemistry ${ }^{17}$ (ressalte-se que, em 2009, em editorial no Journal of the Brazilian Chemical Society - JBCS em que abordou transgressões éticas nas publicações científicas, Vargas já sugeria a necessidade urgente de um Código de Ética da $\left.\mathrm{SBQ}^{18}\right)$. Finalmente, todo periódico científico deve ter diretrizes éticas abrangentes e claras para os envolvidos, isto é, autores, assessores ad hoc e editores; neste sentido, excetuando-se o $J B C S,{ }^{19}$ as outras publicações da SBQ ainda precisam avançar. Aliás, recentemente Bosch et al. ${ }^{20}$, baseados em um estudo dos sítios de 399 revistas de alto impacto da área biomédica, relataram que somente em um terço deles estavam publicamente disponíveis definições de má conduta. Se todas essas instâncias efetivamente derem sua contribuição, estará consolidada a benéfica ocorrência de contínua educação e difusão sobre boas práticas científicas.

Finalizando, confesso que me abstive, propositalmente, de aqui discutir o que se caracteriza como ética da ciência, pois para tal muita literatura está disponível, incluindo os documentos do CNPq e da FAPESP, em cujas páginas web constam diversas sugestões. Todavia, sugiro a leitura do excelente artigo de Resnik, ${ }^{21}$ disponível no sítio do NIH - National Institute of Health (EUA), agência que desde 1989 requer que alunos de pós-graduação por ela apoiados recebam educação em boas práticas científicas. $^{22}$

\section{REFERÊNCIAS*}

1. Balbachevsky, E. Em Os Desafios da Educação no Brasil; Brock, C.; Swartzman, S., eds.; Nova Fronteira: Rio de Janeiro, 2005, cap. 9.

2. Plano Nacional de Pós-Graduação. PNPG 2011-2020. CAPES: Brasília, 2010.

3. Carta do presidente do CNPq (http://www.cnpq.br/documents/10157/ bdaf3c0a-f04b-4174-aa35-208f34bd1d61).

4. Relatório da Comissão de Integridade de Pesquisa do CNPq (http://www. cnpq.br/documents/10157/a8927840-2b8f-43b9-8962-5a2ccfa74dda).

5. Resolução Normativa $n^{\circ}$ 06/2012 (http://www.cnpq.br/web/guest/view/-/ journal_content/56_INSTANCE_0oED/10157/106200).

6. Orientações CAPES - Combate ao Plágio (http://www.capes.gov.br/ images/stories/download/diversos/OrientacoesCapes_CombateAoPlagio. pdf).

7. Comunicado $n^{\circ} 003 / 2011$ - Coordenação da Área de Química - CAPES (http://www.capes.gov.br/images/stories/download/avaliacao/04_quim_ comunicado-03-2011.pdf).

8. Código de Boas Práticas da FAPESP (http://www.fapesp.br/boaspraticas).

9. Revista Pesquisa FAPESP (http://revistapesquisa.fapesp.br).

10. Coelho, F.; Quim. Nova 2006, 29, 186.

11. Torresi, S. I. C.; Pardini, V. L.; Ferreira, V. F.; Quim. Nova 2008, 31, 197.

12. Torresi, S. I. C.; Pardini, V. L.; Ferreira, V. F.; Quim. Nova 2009, 32, 1371.

13. Torresi, S. I. C.; Pardini, V. L.; Ferreira, V. F.; Quim. Nova 2011, 34, 371

14. Torresi, S. I. C.; Pardini, V. L.; Ferreira, V. F.; Quim. Nova 2011, 34, 1489.

15. Gunsalus, C. K.; Sci. Eng. Ethics 1998, 4, 51.

16. Ethical and Professional Guidelines - American Chemical Society (http://portal.acs.org/portal/acs/corg/content?_nfpb=true\&_ pageLabel=PP_TRANSITIONMAIN\&node_id $=1095 \&$ use sec=false\&sec_url_var=region $1 \&$ __uuid=91cd2af9-8fda-4e $82-9 \mathrm{f} 4 \mathrm{e}-$ 9f36871ffbe4).

17. Code of Conduct - Royal Society of Chemistry (http://www.rsc.org/ Membership/CodeofConduct.asp).

18. Vargas, M. D.; J. Braz. Chem. Soc. 2009, 20(10), iii.

19. Ethical Guidelines - Journal of the Brazilian Chemical Society (http:// jbcs.sbq.org.br/conteudo.asp?page $=19$ ).

20. Bosch, X.; Hernández, C.; Pericas, J. M.; Doti, P.; Marusic, A.; PLoS ONE 2012, 7, e51928 (doi:10.1371/journal.pone.0051928).

21. Resnick, D. B.; "What is ethics in research \& why is it important?" (http://www.niehs.nih.gov/research/resources/bioethics/whatis).

22. Resnick, D. B.; "Research ethics timeline (1932-present)" (http://www. niehs.nih.gov/research/resources/bioethics/timeline/index.cfm).

* Todas as páginas web citadas foram acessadas em 18/3/2013 